\title{
Determination of capsaicinoids in peppers by microwave-assisted extraction-high-performance liquid chromatography with fluorescence detection
}

\author{
Gerardo F. Barbero, Miguel Palma*, Carmelo G. Barroso \\ Grupo de Investigación Químico Analítica del Vino y Productos Agroalimentarios, Departamento de Química Analitica, \\ Facultad de Ciencias, Universidad de Cádiz, Apartado 40, 11510 Puerto Real, Cádiz, Spain \\ Received 30 March 2006; received in revised form 27 June 2006; accepted 28 June 2006 \\ Available online 4 July 2006
}

\begin{abstract}
A new method has been developed for the extraction of capsaicinoids (nordihydrocapsaicin, capsaicin, dihydrocapsaicin, homocapsaicin and homodihydrocapsaicin) in peppers employing microwave-assisted extraction. The parameters studied are: extraction solvent (methanol, ethanol, acetone, ethyl acetate and water), temperature $\left(50-200^{\circ} \mathrm{C}\right)$, sample quantity $(0.1-1 \mathrm{~g})$, volume of solvent $(15-50 \mathrm{~mL})$ and the extraction time (5-20 min). The results found for the optimum conditions are: $125^{\circ} \mathrm{C}$ as extraction temperature, $25 \mathrm{~mL}$ of solvent, $0.5 \mathrm{~g}$ of freshly triturated peppers and extraction for $5 \mathrm{~min}$, employing $100 \%$ ethanol as solvent. The capsaicinoids obtained were stable under the optimised extraction conditions. The resulting method presents a high degree of reproducibility (R.S.D. $<6 \%$ ).
\end{abstract}

(c) 2006 Elsevier B.V. All rights reserved.

Keywords: Microwave-assisted extraction; Capsaicinoids; Peppers

\section{Introduction}

Hot or spicy peppers are savoury food additives that are widely utilised in many parts of the world, and are highly valued for their attributes of colour, pungency, and aroma. Capsaicinoids are the compounds responsible for the hot, spicy flavour imparted by many peppers. The two majority capsaicinoids present in most varieties of hot peppers are capsaicin (trans8-methyl- $N$-vanillyl-6-nonenamide) and dihydrocapsaicin (8methyl- $N$-vanillylnonanamide) [1]. In addition to these two major capsaicinoids, other minority capsaicinoids are found in hot peppers, such as nordihydrocapsaicin, norcapsaicin, homocapsaicin, homodihydrocapsaicin, nornorcapsaicin, nornornorcapsaicin, and nonivamide, among others [2,3].

The capsaicinoids have several properties and applications that make them very interesting compounds. In particular, they are antimutagenic and antitumoral compounds $[4,5]$, antioxidants [6,7], and are commonly utilised as topical analgesics for many painful clinical conditions [8].

\footnotetext{
* Corresponding author. Tel.: +34 956016775 ; fax: +34 956016460 .

E-mail address: miguel.palma@uca.es (M. Palma).
}

Many techniques for the extraction of capsaicinoids from peppers have been studied, such as maceration [9], magnetic stirring [10], Soxhlet [11,12], ultrasound-assisted extraction [13], extraction by means of supercritical fluids [14], extraction by pressurized liquids [15] and enzymatic extraction [16]. These techniques are employed in response to the increasing demand for methods that allow the extraction process to be automated, extraction times to be shortened, the consumption of solvents to be reduced, and the exposure of operative personnel to solvents to be minimised.

In addition to these techniques, microwave-assisted extraction (MAE) is being employed in extraction processes. This technique consists in applying the energy provided by microwave radiation to accelerate the process of extraction of the analytes in particular matrices. The application employing microwaves that currently is most widely utilised is the extraction of soluble materials from different matrices, generally employing organic solvents $[17,18]$.

This technology finds application not only in analysis laboratories but also in the extraction industry sector. It has been found that extraction of the analytes of interest is performed very rapidly, and characterised by a huge reduction of the energy required and of the solvent consumed. This type of extrac- 
tion offers high degrees of selectivity and sensitivity; in many instances, it increases the percentages of extraction obtained in comparison with conventional extraction techniques like Soxhlet and even with new techniques such as extraction by means of supercritical fluids [19].

The literature contains many studies in which researchers have developed methods for the extraction of organic compounds from matrices of soils [20,21], sediments [22,23], seeds [24] and foods [25,26] employing MAE. These studies demonstrate that these compounds are extracted extremely efficiently when the energy provided by microwaves is employed.

Generally, organic solvents are utilised to extract the organic compounds present in vegetal matrices. Often, a small volume of water is added to the extraction samples since in this way the samples can absorb the microwave radiation more efficiently, which results in the compounds of interest being separated out in less time. Water is also employed in many cases as the extraction solvent when there is a need to extract organic compounds soluble in water [27].

This study evaluates the applicability of using microwaveassisted extraction for obtaining capsaicinoids (nordihydrocapsaicin (n-DHC), capsaicin (C), dihydrocapsaicin (DHC), homocapsaicin (h-C) and homodihydrocapsaicin (h-DHC)) from peppers. Different temperatures, solvents, extraction times, solvent volumes, and quantities of extraction samples have been evaluated. The results obtained have been compared with those obtained using maceration assisted by magnetic stirring.

\section{Experimental}

\subsection{Chemical and reagents}

The solvents (ethanol, acetone and ethyl acetate (Panreac, Barcelona, Spain), methanol and glacial acetic acid (Merck, Darmstadt, Germany)) utilised were of HPLC quality. The water was obtained from a Milli-Q water bidistillation system (Millipore, Bedford, MA, USA). The reference standards of capsaicinoids, capsaicin $(97 \%)$ and dihydrocapsaicin $(90 \%)$ were obtained from Sigma (St. Louis, MO, USA).

\subsection{Plant material}

Hot Cayenne pepper (Capsicum frutescens) was used for the development of the MAE method. The peppers were peeled, and the stalk and seeds were separated from the rest. Only the pericarp and the placenta of the pepper have been used for this study. Both the pericarp and the placenta were triturated with a conventional electric mixer, until a homogeneous sample was obtained for the analysis. The triturated sample obtained was preserved in the freezer at $-20^{\circ} \mathrm{C}$ until analysed.

During the development of the method, a study was made of the stability of the capsaicinoids at different temperatures employing a standardised extract. This extract was obtained by means of ultrasound-assisted extraction of the same hot Cayenne pepper that was utilised for the study of the MAE. The solvent employed to obtain this extract was ethanol.

\subsection{Extraction procedure}

The extraction of capsaicinoids originating from peppers using microwaves was carried out employing different extraction conditions: temperature: $50-200{ }^{\circ} \mathrm{C}$; solvents: methanol, ethanol, acetone, ethyl acetate and water; power: $500 \mathrm{~W}$; volume of solvent: $15-50 \mathrm{~mL}$; sample quantity: $0.1-1 \mathrm{~g}$; extraction time: 5-30 $\mathrm{min}$; and magnetic stirring: $25 \%$.

The MAE process was performed in an Ethos 1600 microwave extractor (Milestone, Shelton, CT, USA).

\subsection{Separation and quantification of capsaicinoids}

The chromatograph employed for the separation was a Dionex HPLC instrument (Sunnyvale, CA, USA) equipped with the following modules: ASI-100 automatic autoinjector; P680 HPLC pump; TCC-100 heating column; RF 2000 fluorescence detector; and UCI-50 universal chromatographic interface. The Chromeleon 6.60 software was used. The chromatographic separation was carried out using a Chromolith Performance RP-18e $(100 \mathrm{~mm} \times 4.6 \mathrm{~mm})$ monolithic column (Merck).

The separation and quantification of the capsaicinoids was performed by developing a high-performance liquid chromatography (HPLC) method with fluorescence detection. For the chromatographic separation a gradient method was utilised, with acidified water $(0.1 \%$ acetic acid as solvent $\mathrm{A})$ and acidified methanol $(0.1 \%$ acetic acid as solvent $\mathrm{B})$ used as separation solvents, working at a flow rate of $6 \mathrm{~mL} \mathrm{~min}^{-1}$. The gradient employed was the following: $0 \mathrm{~min}, 0 \% \mathrm{~B} ; 2 \mathrm{~min}, 50 \% \mathrm{~B}$; $3.5 \mathrm{~min}, 50 \% \mathrm{~B} ; 10 \mathrm{~min}, 70 \% \mathrm{~B} ; 12 \mathrm{~min}, 70 \% \mathrm{~B} ; 15 \mathrm{~min}, 100 \%$ B; $20 \mathrm{~min}, 100 \% \mathrm{~B}$. With respect to the fluorescence conditions utilised for the detection of the capsaicinoids, an excitation wavelength of $280 \mathrm{~nm}$, and an emission wavelength of $310 \mathrm{~nm}$ were utilised. Fig. 1 shows a typical chromatogram obtained using the developed method.

Quantification was performed of the capsaicinoids (nordihydrocapsaicin, capsaicin, dihydrocapsaicin, homocapsaicin and homodihydrocapsaicin) present in three varieties of peppers (hot Cayenne pepper (C. frutescens), long marble pepper (Capsicum annиит) and round marble pepper (C. аппиит)). Capsaicin and dihydrocapsaicin were quantified from the calibration curves obtained from the standard solutions. Since there are no commercial standards of nordihydrocapsaicin, homocapsaicin and homodihydrocapsaicin, these were quantified from the calibration curve of dihydrocapsaicin (for nordihydrocapsaicin and for homodihydrocapsaicin) and from the calibration curve of capsaicin (for homocapsaicin), given the structural similarities between these molecules. Table 1 shows the calibration curves for the capsaicinoids determined by the HPLC method. The limits of detection and of quantification have been calculated using the ALAMIN software [28].

\section{Results and discussion}

\subsection{Stability of capsaicinoids}

One of the advantages of MAE is that the use of high temperatures increases and accelerates the effectiveness of the extraction 


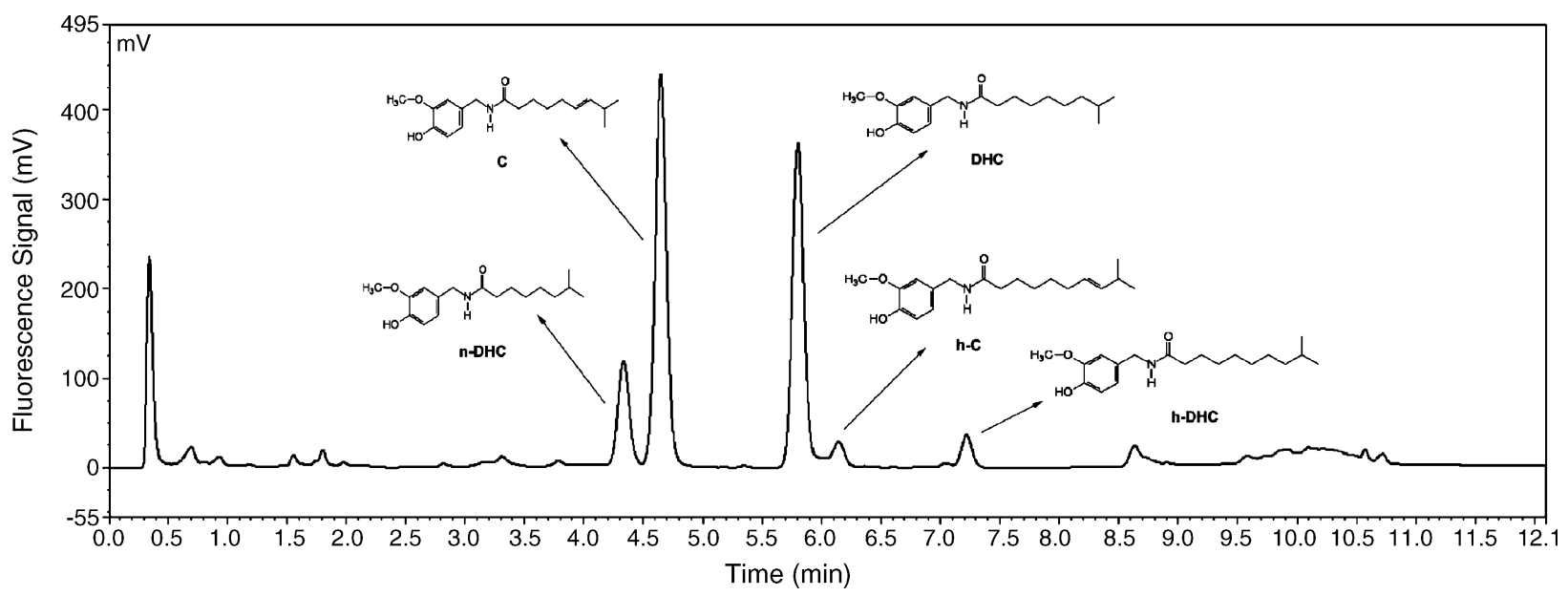

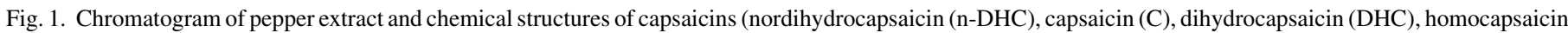
(h-C) and homodihydrocapsaicin (h-DHC). Fluorescence detection: excitation $280 \mathrm{~nm}$, emission $310 \mathrm{~nm}$.

of the compounds of interest from the sample. Temperature is a fundamental parameter in extracting compounds. In this study the aim was to evaluate temperatures ranging from 50 to $200^{\circ} \mathrm{C}$ $\left(50,100,125,150,175\right.$ and $\left.200^{\circ} \mathrm{C}\right)$. For practical reasons, it was proposed that the maximum duration of the extraction method being developed should be $30 \mathrm{~min}$.

Given this, it was proposed initially to perform a study of the stability of the capsaicinoids present in a previously prepared extract. This involved subjecting a mixture of capsaicinoids to the action of microwave radiation, for a period of $30 \mathrm{~min}$, at the different temperatures previously indicated, to determine if the capsaicinoids suffered any degradation. This would allow us to select a suitable extraction temperature that would increase the effectiveness of the extraction without causing degradation of the capsaicinoids.

The stability of the capsaicinoids was studied with $0.5 \mathrm{~mL}$ of extract of concentrated hot Cayenne pepper, $24 \mathrm{~mL}$ of solvent (methanol) and at a power of $500 \mathrm{~W}$, for $30 \mathrm{~min}$ at each of the temperatures previously indicated. Once the $30 \mathrm{~min}$ had elapsed, a volume of $0.5 \mathrm{~mL}$ of internal standard was added for the volume correction.

Fig. 2 presents the average relative concentration $(n=3)$ of the different capsaicinoids present in the extracts subjected to microwave radiation for a period of $30 \mathrm{~min}$ at temperatures ranging from 50 to $200^{\circ} \mathrm{C}$.

From the figure it can be observed that, over the course of 30 min, no degradation is detected of the capsaicinoids up to a temperature of $125^{\circ} \mathrm{C}$. The degradation of the capsaicinoids begins to be seen at $150{ }^{\circ} \mathrm{C}$; in fact, there are three compounds

Table 1

Calibration curves of capsaicin (C) and dihydrocapsaicin (DHC)

\begin{tabular}{lll}
\hline & $\mathrm{C}$ & $\mathrm{DHC}$ \\
\hline Intercept & 187 & 0.54 \\
Slope & 112901 & 151770 \\
Coefficient of regression & 0.9997 & 0.9998 \\
$\mathrm{LD}\left(\mathrm{mg} \mathrm{L}^{-1}\right)$ & 0.008 & 0.011 \\
$\mathrm{LQ}\left(\mathrm{mg} \mathrm{L}^{-1}\right)$ & 0.028 & 0.036 \\
Interval $\left(\mathrm{mg} \mathrm{L}^{-1}\right)$ & $0.017-0.303$ & $0.02-0.417$ \\
\hline
\end{tabular}

that present a significant difference from the reference, and this degradation becomes more marked as the temperature is increased. At $200^{\circ} \mathrm{C}$ a very striking degradation of all the capsaicinoids present in the extract is observed.

Based on these findings, the extraction method developed will take place at $125^{\circ} \mathrm{C}$, to ensure that there will be no degradation of the compounds of interest.

\subsection{Solvent}

The selection of the most suitable solvent for extracting the analytes of interest from the sample matrix is a fundamental step in developing any method of extraction. On the one hand, the effectiveness of MAE will largely depend on the capacity of the extraction solvent for absorbing and transmitting the microwave energy. On the other, the capsaicinoids should be soluble in the solvent that is used for the extraction.

The solvents that have been studied for extracting the capsaicinoids from the sample matrix are methanol, ethanol, acetone, ethyl acetate and water. Methanol, ethanol, acetone and ethyl

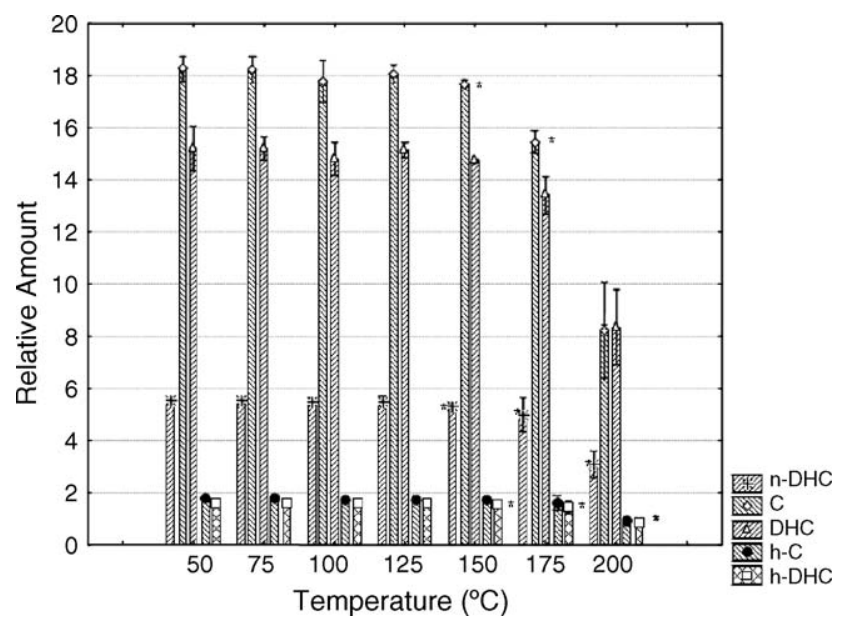

Fig. 2. Relative amounts ( \pm 2 S.D.) of capsaicinoids found using different extraction temperatures in the MAE system $(n=3)$. ${ }^{*}$ Significant differences with respect to the reference, at $95 \%$ confidence level. 


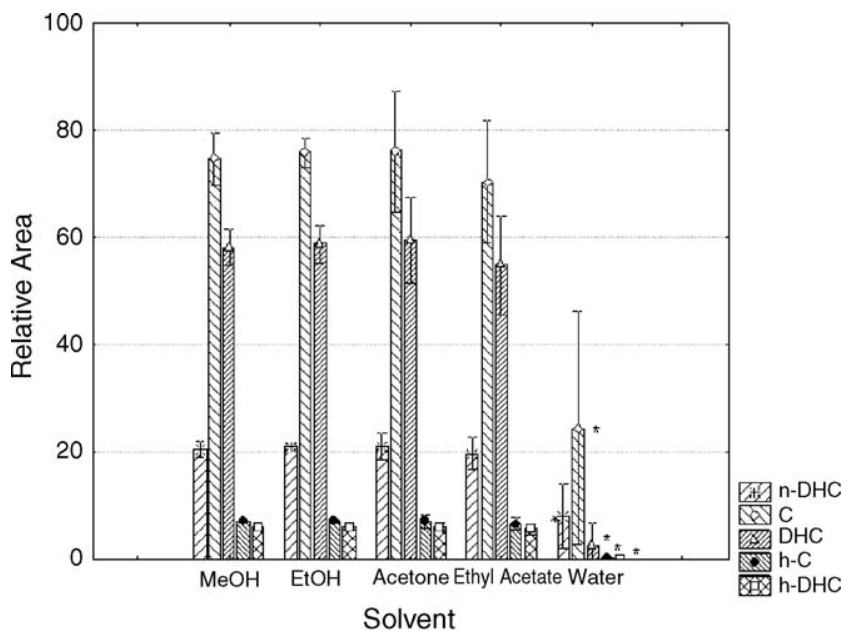

Fig. 3. Results ( \pm 2 S.D.) obtained employing different pure solvents in MAE (areas of capsaicinoids relative to the internal standard area) $(n=3)$. * Significant differences with respect to the maximum recovery at $95 \%$ confidence level.

acetate are solvents that are normally employed for the extraction of capsaicinoids in various different extraction techniques, such as Soxhlet extraction, maceration, and ultrasound-assisted extraction. Water is not a good solvent for extracting capsaicinoids, but its capacity for the extraction of these compounds has been evaluated here since it is a very polar solvent that will be capable of absorbing a large amount of microwave energy; this may therefore facilitate the capsaicinoid extraction process.

The extractions were performed with a sample quantity of triturated hot Cayenne pepper of about $0.5 \mathrm{~g}$, in $25 \mathrm{~mL}$ of solvent, at a temperature of $125^{\circ} \mathrm{C}(500 \mathrm{~W}$ of power) for a period of $10 \mathrm{~min}$ and under magnetic stirring at $25 \%$. All the assays were conducted in triplicate.

Fig. 3 shows the relative chromatographic areas of the different capsaicinoids extracted with the five solvents tested. It can be observed from the graph that methanol, ethanol and acetone could all equally be employed for the extraction of capsaicinoids giving similar results. It was decided to use ethanol since it is less toxic than the others.

In the graph it can also be observed that water, which is a very polar solvent, has only a poor capacity for the extraction of capsaicinoids, despite being a solvent capable of absorbing microwave energy. This effect is accentuated when extracting the less polar capsaicinoids such as dihydrocapsaicin or homodihydrocapsaicin; water extracts a much smaller percentage of these capsaicinoids than of the other more polar capsaicinoids such as nordihydrocapsaicin and capsaicin.

Moreover, it has been proven that, in many instances, the addition of small quantities of water to the extraction solvents improves their extracting properties [29]. For this reason the study was extended to include the addition of specific percentages of water $(0,10,25$ and $50 \%$ water) to ethanol, as the optimum extraction solvent, to determine how the extraction properties of this solvent are modified. The extraction conditions were the same as those employed for the selection of the optimum extraction solvent. Similarly, all the assays were conducted in triplicate.

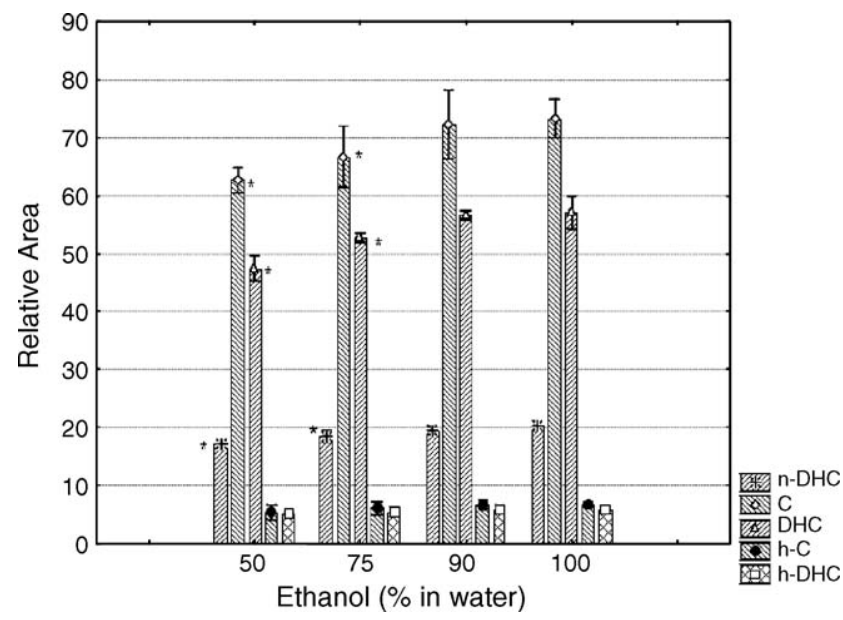

Fig. 4. Results ( \pm 2 S.D.) obtained employing different mixtures of ethanol and water as solvent in MAE (areas of capsaicinoids relative to the internal standard area) $(n=3)$. * Significant differences with respect to maximum recovery, at $95 \%$ confidence level.

In Fig. 4 the relative chromatographic areas of capsaicinoids extracted with ethanol containing different percentages of water $(0,10,25$ and $50 \%$ water $)$ are represented.

It can be observed from Fig. 4 that, in the case of capsaicinoids, the addition of water to the solvent does not improve the extraction properties of ethanol, unlike the effect observed with many other compounds; as the percentage of water in the ethanol is increased, there is a decrease in the quantity of capsaicinoids extracted. This may be because of the good solubility of capsaicinoids in ethanol, which diminishes as the polarity of the solvent is increased by the addition of more water.

\subsection{Extraction time}

Generally, by increasing the extraction time, the quantity of analytes extracted is increased, although there is the risk that degradation may occur.

To determine the time needed to obtain complete extractions, extractions of samples of peppers were performed for different lengths of time. Extraction times of 5, 10, 15, and 20 min were evaluated. The rest of the variables employed were: temperature of $125^{\circ} \mathrm{C}, 500 \mathrm{~W}$ of power, ethanol as extraction solvent, $25 \mathrm{~mL}$ of solvent, magnetic stirring at $25 \%$, and approximately $0.5 \mathrm{~g}$ of sample. All the assays were conducted in triplicate. The results obtained are given in Fig. 5.

As confirmed in Fig. 5, a clear increase of the recovery of capsaicinoids was not obtained with the increase of the extraction time. In fact, there are no significant higher recoveries at longer extraction time. Therefore, 5 min was selected as the extraction time, since this is sufficient to extract all the capsaicinoids present in fresh samples of peppers.

\subsection{Volume of solvent}

The ratio of mass/volume of solvent is a factor that must be studied to increase the effectiveness of extraction of capsaicinoids employing microwave-assisted extraction. For the 


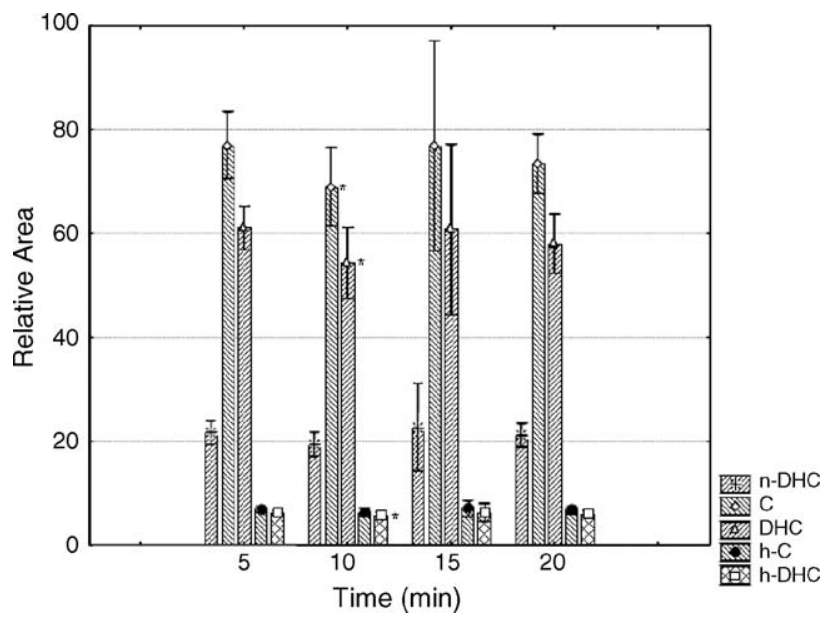

Fig. 5. Results ( \pm 2 S.D.) obtained employing different extraction times in MAE (areas of capsaicinoids relative to the internal standard area) $(n=3)$. * Significant differences with respect to the maximum recovery, at $95 \%$ confidence level.

conventional techniques of solid-liquid extraction, the tendency is to reduce the ratio of mass/volume of solvent, and in many instances this increases the extraction volume obtained. When this happens, the improvement is due to there being a greater volume of solvent to extract the same quantity of solute.

To evaluate the effect of the volume of the solvent on the extraction, a series of extractions were carried out with different volumes of solvent $(15,25,40$ and $50 \mathrm{~mL})$. The rest of the extraction conditions were: temperature of $125^{\circ} \mathrm{C}, 500 \mathrm{~W}$ of power, approximately $0.5 \mathrm{~g}$ of sample, magnetic stirring at $25 \%$, and ethanol as extraction solvent. All the assays were conducted in triplicate. There were no significant differences when the volume of the extraction solvent is varied. Therefore, the variable of solvent volume will not be a determining factor when extracting capsaicinoids in these conditions. It was decided to work with a volume of $25 \mathrm{~mL}$ since this enables chromatographic peaks to be obtained with sufficient area to minimise the errors of chromatographic integration.

\subsection{Quantity of sample}

Once the volume of extraction solvent had been studied, the next step was to optimise the quantity of sample, the other factor influencing the ratio of mass/volume of solvent previously considered. In general, by reducing the quantity of sample while holding the volume constant, the quantities of analytes extracted are increased, since the ratio of mass/volume of solvent is diminished.

In this study sample quantities of $0.1,0.2,0.5$ and $1 \mathrm{~g}$ of peppers have been evaluated, while maintaining the volume constant at $25 \mathrm{~mL}$ of ethanol. The other extraction parameters utilised were: temperature of $125^{\circ} \mathrm{C}, 500 \mathrm{~W}$ of power, $25 \mathrm{~mL}$ of ethanol, magnetic stirring at $25 \%$, and extraction for a period of $5 \mathrm{~min}$. All the assays were conducted in triplicate.

The results obtained are given in Fig. 6, in which the relative quantities of capsaicinoids extracted with different sample quantities $(0.1,0.2,0.5$ and $1 \mathrm{~g})$ are represented.

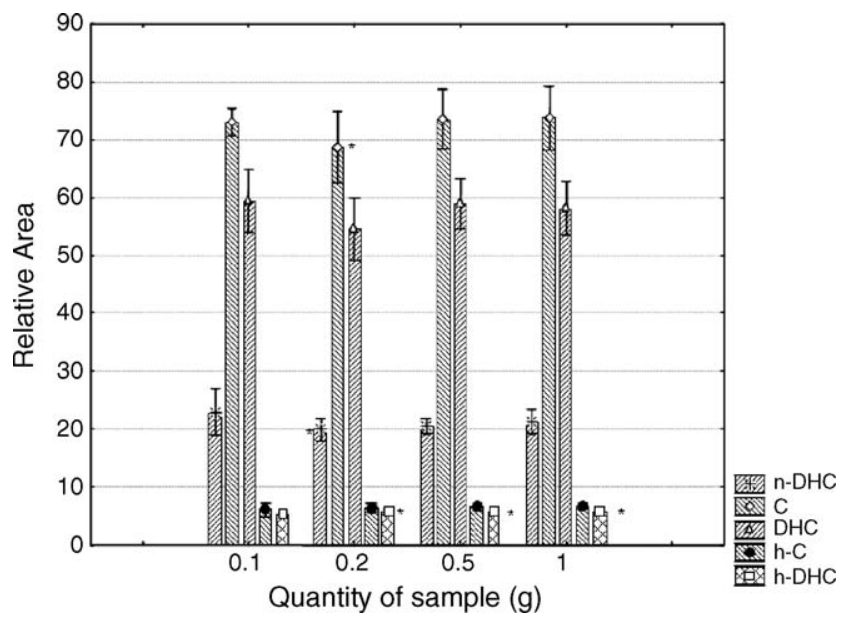

Fig. 6. Results ( \pm 2 S.D.) obtained employing different quantities of sample in MAE (areas of capsaicinoids relative to the internal standard area) $(n=3)$. *Significant differences with respect to the reference, at $95 \%$ confidence level.

It is observed that the quantity of sample is not a relevant parameter. Thus it was decided to employ $0.5 \mathrm{~g}$ since this was found to be a sample quantity that produces chromatographic peaks of sufficient area to allow reliable integrations.

\subsection{Reproducibility and repeatability of the method}

The repeatability and reproducibility of the method developed has been studied. For this a total of 12 extractions were performed, distributed as follows: six extractions performed on the first day of the study and three more extractions on each of the following 2 days.

The extraction conditions that were employed are the optimum conditions that have been developed in this study, and are as follows-power: $500 \mathrm{~W}$; time: $5 \mathrm{~min}$; solvent: ethanol; temperature: $125^{\circ} \mathrm{C}$; quantity of sample: $0.5 \mathrm{~g}$; volume of solvent: $25 \mathrm{~mL}$; magnetic stirring: $25 \%$.

Table 2

Repeatability $(n=6)$ and reproducibility $(n=9)$ of the method developed for the capsaicinoids analysed

\begin{tabular}{llllll}
\hline & n-DHC & C & DHC & h-C & h-DHC \\
\hline R.S.D. (\%) intraday & 1.98 & 1.99 & 2.37 & 2.99 & 3.04 \\
R.S.D. (\%) interday & 4.06 & 4.84 & 5.28 & 5.92 & 5.53 \\
\hline
\end{tabular}

Table 3

Quantities ( $\mu \mathrm{mol} \mathrm{kg}{ }^{-1}$ ) of capsaicinoids found employing different times, in the extraction by means of magnetic stirring and by MAE

\begin{tabular}{cccccc}
\hline Time (min) & n-DHC & Capsaicin & DHC & h-C & h-DHC \\
\hline \multicolumn{2}{l}{ Magnetic stirring extraction } & & & & \\
5 & 80.9 & 391.0 & 226.9 & 26.8 & 37.9 \\
10 & 88.1 & 423.7 & 246.3 & 28.7 & 41.2 \\
15 & 91.4 & 439.0 & 256.9 & 29.3 & 42.8 \\
20 & 92.0 & 440.8 & 261.4 & 29.3 & 43.1 \\
25 & 93.4 & 445.7 & 256.9 & 29.7 & 43.7 \\
MAE & & & & & \\
30 & 93.8 & 448.4 & 265.1 & 29.7 & 46.8 \\
5 & 93.8 & 451.6 & 265.4 & 29.6 & 46.9 \\
\hline
\end{tabular}


Table 4

Quantity ( $\mu \mathrm{mol})$ of capsaicinoid per kilogram of fresh pepper in the samples analysed $(n=3)$

\begin{tabular}{llllll}
\hline Pepper & n-DHC & C & DHC & h-C & h-DHC \\
\hline Cayenne & $93.8 \pm 6.6$ & $451.6 \pm 32.8$ & $265.4 \pm 18.1$ & $29.6 \pm 1.7$ & nd \\
LM & $40.3 \pm 2.7$ & $378.8 \pm 24.3$ & $185.6 \pm 10.3$ & $18.9 \pm 2.4$ \\
RM & $23.2 \pm 1.4$ & $265.2 \pm 16.8$ & $132.4 \pm 8.0$ & nd & $15.8 \pm 0.6$ \\
\hline
\end{tabular}

LM: long marble pepper; RM: round marble pepper; nd: not detected.

The results obtained expressed in percentage scores for the repeatability and for the reproducibility are given in Table 2 .

\subsection{Comparison of MAE with extraction by means of magnetic stirring}

The method of microwave-assisted extraction of capsaicinoids in peppers developed in this study was compared with a method of conventional extraction of capsaicinoids using magnetic stirring that had already been developed previously in our research group.

For this the capsaicinoids present in hot Cayenne pepper (the pepper utilised for the development of the MAE method) were extracted during different times of extraction $(5,10,15,20,25$ and $30 \mathrm{~min}$ ). The solvent utilised was ethanol, and the temperature of extraction was $25^{\circ} \mathrm{C}$, in order to avoid evaporation of the ethanol at higher temperatures.

The results obtained for the extraction of the capsaicinoids for different periods of time are given in Table 3. The quantities found for each capsaicinoid at different extraction times employing magnetic stirring are presented.

By using this technique a minimum of $15 \mathrm{~min}$ is needed to obtain extractions of more than $95 \%$ of the quantities of capsaicinoids that are obtained with $30 \mathrm{~min}$ of extraction employing magnetic stirring or by using MAE ( $5 \mathrm{~min})$.

\subsection{Quantification of the capsaicinoids present in different samples of peppers}

Table 4 gives the quantities of capsaicinoids present in the different varieties of peppers studied. It can be observed that, of the three varieties of peppers studied, it is hot Cayenne pepper that contains the largest amount of capsaicinoids, followed by the round marble pepper and lastly by the long marble pepper. Homocapsaicin was only found in hot Cayenne pepper; neither of the other two varieties studied (round and long marbles) contained this compound. Similar differences have been also found between very hot varieties and hot varieties [30]; however, there are some studies demonstrating that homocapsaicin is only produced in the latest stages of the plant development [31]. So, it cannot be concluded that homocapsaicin is not going to be found in long and round marbles pepper, if harvested at different degree of plant development.

\section{Conclusions}

A fast and quantitative method has been developed for the extraction of capsaicinoids from fresh samples of peppers utilis- ing microwave-assisted extraction; no degradation of these compounds was observed up to $150^{\circ} \mathrm{C}$. The parameters determined for the extraction of capsaicinoids are the following: $125^{\circ} \mathrm{C}$, $500 \mathrm{~W}, 25 \mathrm{~mL}$ of solvent, $0.5 \mathrm{~g}$ of triturated fresh peppers, $5 \mathrm{~min}$ extraction time, and $100 \%$ ethanol as optimum extraction solvent. The method developed has been employed to perform the quantification of the capsaicinoids present in several different varieties of hot peppers cultivated in Spain. The method developed has relative standard deviation for repeatability of 3.04\% as a maximum, and for reproducibility of less than $6 \%$. In a comparison made between the method developed using MAE, and a traditional method of extraction such as magnetic stirring, it was confirmed that MAE is a much faster method.

\section{Acknowledgements}

G.F. Barbero gratefully thanks the Ministerio de Educación y Ciencia for a doctoral scholarship. This study was supported by the CICYT (project BIO2000-1091-C02-02).

\section{References}

[1] A. Laskaridou-Monnerville, J. Chromatogr. A 838 (1999) 293.

[2] H.L. Constant, G.A. Cordell, J. Nat. Prod. 59 (1996) 425.

[3] H.L. Constant, G.A. Cordell, J. Nat. Prod. 58 (1925).

[4] Y.J. Surh, S.S. Lee, Food Chem. Toxicol. 34 (1996) 313.

[5] C.R. Agrawal, M. Wiessler, E. Hecker, V.S. Vides, Int. J. Cancer 38 (1986) 689.

[6] K. Murakami, M. Ito, H.H. Htay, R. Tsubouchi, M. Yoshino, Biomed. Res. Tokyo 22 (2001) 15.

[7] D.E. Henderson, A.M. Slickman, J. Agric. Food Chem. 47 (1999) 2563.

[8] E. Kaale, A.V. Schepdael, E. Roets, J. Hoogmartens, J. Pharm. Biomed. Anal. 30 (2002) 1331.

[9] P. Kirschbaum-Titze, C. Hiepler, E. Mueller-Seitz, M. Petz, J. Agric. Food Chem. 50 (2002) 1260.

[10] M. Contreras-Padilla, E.M. Yahia, J. Agric. Food Chem. 46 (1998) 2075.

[11] F. Korel, N. Bagdatlioglu, M.Ö. Balaban, Y. Hisil, J. Agric. Food Chem. 50 (2002) 3257.

[12] A.M. Krajewska, J.J. Powers, J. Chromatogr. 409 (1987) 223.

[13] R. Karnka, M. Rayanakorn, S. Watanesk, Y. Vaneesorn, Anal. Sci. 18 (2002) 661.

[14] H.G. Daood, V. Illés, M.H. Gnayfeed, B. Mészáros, G. Horváth, P.A. Biacs, J. Supercrit. Fluids 23 (2002) 143.

[15] G.F. Barbero, M. Palma, C.G. Barroso, J. Agric. Food Chem. 54 (2006) 3231.

[16] R.I. Santamaría, M.D. Reyes-Duarte, E. Bárzana, D. Fernándo, F.M. Gama, M. Mota, A. López-Munguía, J. Agric. Food Chem. 48 (2000) 3063.

[17] X. Pan, H. Liu, G. Jia, Y.Y. Shu, Biochem. Eng. J. 5 (2000) 173.

[18] J.H. Kwon, J.M.R. Bélanger, J.R.J. Paré, J. Agric, Food Chem. 51 (2003) 1807.

[19] M.J. Alfaro, J.M.R. Bélanger, F.C. Padilla, J.R. Jocelyn Paré, Food Res. Int. 36 (2003) 499. 
[20] J.L. Luque-García, M.D. Luque de Castro, J. Chromatogr. A 998 (2003) 21.

[21] M.C. Wei, J.F. Jen, J. Chromatogr. A 1012 (2003) 111.

[22] M. Ericsson, A. Colmsjö, J. Chromatogr. A 964 (2002) 11.

[23] O.S. Fatoki, R.O. Awofolu, J. Chromatogr. A 983 (2003) 225.

[24] N. Hong, V.A. Yaylayan, G.S.V. Raghavan, J.R.J. Pare, J.M.R. Belanger, Nat. Prod. Lett. 15 (2001) 197.

[25] G.A.C. Kiss, E. Forgács, T. Cserháti, T. Mota, H. Morais, A. Ramos, J. Chromatogr. A 889 (2000) 41.

[26] M.L. Fishman, H.K. Chau, P. Hoagland, K. Ayyad, Carbohydr. Res. 323 (2000) 126.
[27] Z. Guo, Q. Jin, G. Fan, Y. Duan, C. Qin, M. Wen, Anal. Chim. Acta 436 (2001) 41

[28] A.M.G. Campana, L.C. Rodríguez, F.A. Barrero, M.R. Ceba, J.L.S. Fernández, Trends Anal. Chem. 16 (1997) 381.

[29] M.A. Rostagno, M. Palma, C.G. Barroso, J. Chromatogr. A 1012 (2003) 119.

[30] N. Kozukue, J.-S. Han, E. Kozukue, S.-J. Lee, J.-A. Kim, K.-R. Lee, C.E. Levin, M. Friedman, J. Agric. Food Chem. 53 (2004) 9172.

[31] B. Estrada, M.A. Bernal, F. Pomar, F. Merino, Acta Aliment. 30 (2001) 373 